\title{
The Use of This + Noun by Korean EFL Writers: Focusing on Shell Nouns and Nominalization
}

\author{
Choongil Yoon \\ (Dongguk University Gyeongju Campus)
}

\begin{abstract}
Yoon, Choongil. (2017). The Use of This + Noun by Korean EFL Writers: Focusing on Shell Nouns and Nominalization. Language Research, 53.1, 135-161.
\end{abstract}

\begin{abstract}
The study investigated the use of this + noun as a textual device for creating cohesion and constructing stance in corpora of argumentative essays in English written by Korean university students and native speaker students. Focusing on the uses and distributions of shell nouns and nominalizations within the demonstrative construction, the study examined how they differed in the two corpora. In addition, the study identified major patterns of inappropriate use of this + noun by the Korean student writers. Results showed that while the Korean university students made much less use of this + noun for text reference, their use of shell nouns was less successful in creating cohesion and incorporating stance in ways valued in academic writing. Moreover, the limited range of general nouns used in the construction indicates the Korean writers' use of shell nouns was often habitual rather than strategic. This paper concludes by discussing pedagogical implications of the findings.
\end{abstract}

Keywords: Demonstrative, Shell noun, Nominalization, Argumentative writing, Corpus linguistics

\section{Introduction}

English demonstrative this has enjoyed considerable attention from English for Academic Purposes (EAP) and second and foreign language (L2) writing researchers for its functions as a cohesive device and its highly frequent use in academic prose (e.g., Biber et al. 1999; Charles 2003; Geisler et al.1985; Gray 2010; Swales 2005; Wulff et al. 2012). Used 
as either a pronoun or a determiner as seen in (1a) and (1b) below, this can refer anaphorically to a stretch of the preceding discourse that often goes beyond a noun phrase (NP). (The sentences are from Swales 2005).

(1) The students said they wanted more tests.

(1a) This surprised the instructor.

(1b) This request surprised the instructor.

While research into the anaphoric use of this has been mainly focused on factors that influence a choice between this used as a pronoun (termed "unattended" by Geisler et al. 1985) and this as a determiner followed by an NP ("attended", Geisler et al. 1985), a growing body of EAP research has looked into the types of nouns that accompany this and their roles in text (e.g., Charles 2003; Gray 2010; Gray \& Cortes 2011, S-Y Oh 2012). These studies found that a noun paired with this can be used as an important rhetorical tool for reconceptualizing or highlighting a certain aspect of the referent, therefore influencing the reader's understanding of the given proposition. Research has identified shell nouns as playing such a role in the this + noun construction. A shell noun used as the head noun of the construction encapsulates the preceding proposition (e.g., request in (1b) above) and often reveals the writer's stance towards it (Charles 2003; Swales 2005).

Nominalization is a linguistic feature that can be observed often in the shell nouns occurring in this demonstrative construction. Defined as a major form of grammatical metaphor (GM), (Halliday \& Martin 1993), nominalization reconstrues processes and properties (normally represented by verbs and adjectives) as entities (expressed as nouns). By transforming an action or quality into a static object that can be further evaluated and discussed, nominalization is considered a key resource for cohesion and argument development in academic prose (Halliday \& Martin 1993; Ryshina-Pankova 2010).

As such, the this + noun construction is a lexico-grammatical context where these cohesive devices of academic writing frequently occur. The ability to make effective and appropriate nominal choices in the con- 
struction may therefore help English as a foreign/second language (EFL/ESL) writers in higher education make their arguments more cohesive and convincing in ways valued in academic writing. Support for learners may start from exploring how these features are used by learners with an aim to draw insights into general and specific help learners need.

Motivated by this idea, the present study examined how Korean university students used the this + noun construction in their argumentative essays in English and the extent and manners of their use of shell nouns and nominalization therein. The results of analysis were then compared with data from a corresponding native speaker (NS) corpus of argumentative writing.

\section{Literature Review}

\subsection{Demonstrative this as a cohesive device}

The demonstrative this (and its plural form these) is normally used for drawing attention to a referent and creating cohesion through this reference (Halliday \& Hasan 1976). Unlike the pronoun $i t$, which normally refers back to a specific noun phrase, this, alone and followed by a noun, can have a non-nominal antecedent, which can be any stretch of text including a verb phrase (VP), clause, and sentence (Petch-Tyson 2000; Swales 2005). For example, this in (1a) presented in Introduction refers to the whole sentence of (1). Termed "text reference" (Halliday \& Hasan 1976) or "situation reference" (Petch-Tyson 2000) in the literature, this type of reference is suggested as an effective and handy device for condensing the complex information in the preceding discourse into a nominal phrase and creating textual cohesion by expanding upon it in subsequent propositions.

One of the key issues regarding the use of this in academic writing has been whether and when the demonstrative should be used alone as a pronoun or together with a noun as a determiner (Geisler et al. 1985; S-Y Oh 2012; Swales 2005). Many popular style manuals and EAP instructors have usually cautioned against using this unattended (i.e., as 
a pronoun) as it may generate unnecessary ambiguity about what exactly is referred to by it. However, corpus-based studies in recent years (Gray 2010; Gray \& Cortes 2011; Swales 2005; Wulff et al. 2012) revealed high degrees of pronominal use of this/these (20 to $30 \%$ ) by expert writers.

When it comes to attended this, which is the focus of the present study, researchers have examined what types of nouns follow this and what functions these nouns have in creating referential cohesion. They found that among different types of nouns, shell nouns paired with this function as an effective device for text reference. Their definitions and functions are discussed in more detail in the following section.

\subsection{Shell nouns attending this}

Going under different names such as general nouns (Halliday \& Hasan 1976), carrier nouns (Ivanic 1991), retrospective labels (Francis 1994), and enumerative nouns (Hinkel 2001), shell nouns refer to a functional class of abstract nouns that have only general meanings on their own (e.g., concept, issue, fact, and problem), but whose meanings become specific by the context in which they are used. This specificity is created by three functions of shell nouns: "the semantic function of characterizing complex chunks of information, the cognitive function of temporary concept-formation, and the textual function of linking these nominal concepts with clauses which contain the actual details of information" (Schmid 2000:14). Schmid identified the this + NP construction is one of the lexico-grammatical patterns where shell nouns are typically used (ibid.). When used in this pattern in particular, a shell noun provides a conceptual shell that encapsulates information of the preceding discourse by characterizing it with a specific label and is then expanded upon in the subsequent proposition. Example sentences (1) to (1b) introduced earlier again show how a shell noun in the demonstrative structure works. The entire content of sentence (1) is condensed into the label this request in (1b), which serves as the topic of the next proposition. As such, combined with a shell noun, the cohesive function of this becomes clearer while the referent becomes more specific (Gray 2010). 
However, the role of a shell noun within the demonstrative construction goes beyond a cohesive device. It can be an effective resource for constructing stance and creating authorial voice as well (Charles 2003). That is, through a specific label the writer uses in characterizing the antecedent, his or her evaluation or stance towards it can be expressed. If we look at the example sentences of (1) and (1b) again, the writer may formulate the proposition using different labels as in (1c) and (1d) below:

(1) The students said that they wanted more tests.

(1b) This request surprised the instructor.

(1c) This demand surprised the instructor.

(1d) This hope surprised the instructor. (Swales 2005)

As shown above, the same content can be labeled differently (i.e., request, demand or hope) depending on the writer's epistemic (e.g., certainty, doubt, precision) or attitudinal (e.g., attitudes, feelings) stance towards it (Charles 2003; Francis 1994). By signaling his or her stance this way, the writer indicates to the reader how the preceding proposition should be interpreted or understood, thereby facilitating effective argumentation. Charles (2003) argues that in doing so in academic discourse, writers present themselves as knowledgeable members of their disciplines.

Most corpus studies of this and other demonstratives used in different genres and registers commonly found that the this/these + shell noun structure is a relatively frequent feature in academic writing employed for anaphoric reference and for stance construction. In a series of corpus studies examining the uses of this and these in published journal articles from different academic disciplines, Gray (2010) and Gray and Cortes (2011) found that shell nouns accounted for $40-45 \%$ of all nouns attending the demonstratives and that they were in large part disciplinary-neutral with many shared across different disciplines, which, the researchers argue, illustrates the functional role of shell nouns as a discourse organizer commonly employed in academic prose. In contrast, Charles's (2003) study, focusing on stance construction through the this + shell noun pattern, found disciplinary differences in the types of stance expressed by shell 
nouns. For example, while most stance nouns in the science discipline corpus she examined were of epistemic nature expressing doubt, certainty, and precision, the social science corpus contained a good portion of attitudinal stance nouns expressing feelings and attitudes. The researcher suggests the findings reflect the differences in research practices and ways in which knowledge is constructed in each discipline.

Studies cited above were based on corpora of expert writers' (mostly native speakers') texts and there are only a few studies that examined the corpora of EFL/ESL learners. Although not exclusively on the this + noun pattern, the studies compared the uses of demonstratives (Petch-Tyson 2000), cohesive devices (Hinkel 2001), and this/these as determiners and pronouns (S-Y. Oh 2012) between NS writers (or experts) and non-native speaker (NNS) writers (or students). These studies showed that NNS writers used the this + noun construction as a cohesive device less frequently and that they used only a limited range of nouns in the pattern. Their qualitative analyses also revealed that the uses of shell nouns by NNS students were often not as effective as those by NS counterparts in terms of creating cohesion and constructing stance.

\subsection{Nominalization and grammatical metaphor (GM)}

The cohesive and rhetorical functions of a shell noun paired with this may be examined from the perspective of nominalization and GM, a linguistic phenomenon closely associated with nominalization in systemic-functional linguistics (SFL)1). Nominalization is, as the word itself suggests, a process or outcome of converting something non-nominal into a nominal form. It is considered "metaphoric" due to the incongruence between the semantic categories and their lexico-grammatical realizations. Specifically, nominalization turns processes and properties, which are normally represented by verbs and adjectives, into entities (Halliday \& Martin 1993; Ryshina-Pnakova 2010), thereby treating actions and qualities as

1) Discussing theory of and around GM, which has been well-established in SFL, is way beyond the scope of this study (for seminal work on GM, see Halliday and Martin (1993)). In this paper, nominalization and GM are only discussed to the extent that they are relevant to the this + noun construction. 
abstract objects. The metaphor here is realized lexico-grammatically through transcategorization. Sentences (2)-(3) below illustrate this transformation:

(2) Crime was increasing rapidly across the country, $\cdots$

(2a) the sudden increase in crime was crucial in moving public opinion..

(3) the global financial system is increasingly unstable ...

(3a) this instability may lead to further deterioration of ...

Nominalization is one of the hallmarks of modern academic text, especially text of science, characterized by compressed discourse centering on NPs (Baratta 2010; Biber \& Gray 2010; Halliday \& Martin 1993). As can be seen in the examples above, nominalization functions as an effective cohesive device by packaging the previous discourse expressed in a clause or sentence into a single nominal in subsequent propositions serving as given information. However, as GM, a nominalization goes beyond simply functioning as a cohesive device and serves as a resource for rhetorical effect. By reconstruing dynamic processes as static entities, nominalization presents the stated experience as an object which is further to be described, analyzed and evaluated. The resulting compressed NP-based phrases make the text sound impersonal and objective and at the same time present the content as given facts difficult to dispute (Liardét 2013; Ryshina-Pankova 2010).

As apparent from the brief overview of nominalization above, this textual phenomenon shares a lot with the concept of shell noun in terms of the functions they serve in academic prose: as a cohesive device and a resource for argumentation. In fact, nominalizations are one major type of shell nouns occurring in the this + noun construction as seen in the examples (2)-(3). However, GM has not been examined much in conjunction with shell noun in the literature. There are only a few studies investigating the use and development of GM in academic writing by ESL/EFL learners (Liardét 2013, 2015; Schleppegrell 2004). These studies commonly found that although there was a general tendency of increase in frequency and functions of GM from lower to higher levels of profi- 
ciency, the potential of GM to construe meanings in ways valued in academic texts were largely unrealized even at advanced levels suggesting more explicit instruction on nominal-oriented text development.

\subsection{Research questions}

Despite the important roles of shell nouns and nominalization in constructing written texts in terms of text cohesion, information packaging, and argument development in academic writing, not much research attention has been directed to Korean EAP learners and EFL writers in tertiary education. Motivated by this lack of attention, the present study investigated the use of the this + noun construction and the use of shell nouns and nominalization within that construction in a corpus of Korean university students' English argumentative writing. In addition, by comparing the data from the Korean corpus with those from a corresponding corpus of US and British university students' argumentative writing, the study sought to find the areas and extent of deviation from NS norms, thereby seeking pedagogical insights. The study was guided by the following specific research questions:

1. How frequently does the this + noun construction occur in a corpus of Korean EFL university students' English argumentative essays and a corresponding corpus of NS writing?

2. What types of nouns follow this in the two corpora?

3. How are shell nouns and nominalizations used in the essays in creating cohesion and constructing stance?

4. What are the frequent patterns of inappropriate use of the this + noun construction in the Korean students' essays? 


\section{Method}

\subsection{Corpora}

For the present study, the argumentative essay component of Neungyule Interlanguage Corpus of Korean Learners of English (NICKLE)2) was used. NICKLE is a million-word corpus compiled as part of the Neungyule-Longman English-Korean Dictionary project in 2009. The source text data were collected from the first- and second-year undergraduate students at intermediate levels from multiple universities across South Korea. The argumentative essay component consisted of 425 essays by 342 writers (about 190,000 words). For an NS reference corpus, the Louvain Corpus of Native English Essays (LOCNESS) was used, which is made up of argumentative, expository and literary essays written by British and American university students who were native speakers of English. Only the argumentative essay component was selected (about 230,000 words from 321 essays) for compatibility with the NICKLE subcorpus. The vast majority of the essays in both subcorpora were written on popular argumentative topics such as euthanasia, death penalty, and environmental protection. Table 1 below summarizes the details of the two subcorpora of argumentative essays, which are hereafter referred to as NICKLE and LOCNESS respectively.

Table 1. Profile of the Two Corpora

\begin{tabular}{c|c|c|c}
\hline Corpus & Word tokens & Number of texts & Number of writers \\
\hline \hline NICKLE (argumentative) & 190,252 & 425 & 342 \\
\hline LOCNESS (argumentative) & 229,505 & 321 & 321 \\
\hline
\end{tabular}

\subsection{Data Analysis}

To answer the research questions, analysis was conducted in the following steps. As the first step, to locate and count instances of the this +

2) The corpus is freely available upon request. For more information about the corpus, go to https://uclouvain.be/en/research-institutes/ilc/cecl/learner-corpora-around-theworld.html. 
noun construction, the two corpora were tagged for part of speech. To extract nouns used in the construction, syntactic patterns of this + noun, this + modifier + noun, and this + up to 3 intervening words + noun were searched for with regular expressions. These patterns were included to retrieve the instances of modification (i.e., adjectival or nominal modifier + noun), compound nouns (e.g., side effect), double headed nouns (e.g., point of view), and species nouns (e.g., kind/type/form of + noun). For the tagging and counting of the data, the Multidimensional Analysis Tagger (Version 1.2) (Nini 2014) and AntConc (Version 3.4.3) (Anthony 2014) were used.

Next, extracted instances were manually checked to identify true hits of attended this and nouns from the true hits were classified into different types according to a coding scheme adapted from previous studies (Charles 2003; Francis 1994; Gray \& Cortes 2011; Liardét 2015). Nouns that attended this were coded into three broad categories. Each category and typical example drawn from the corpora are provided below. Abstract nouns were coded as Shell Noun if they referred to a stretch of the preceding text that extends beyond a single nominal element, encapsulating the whole or part of the proposition expressed therein. The noun here is not a repetition, paraphrase or synonym of a preceding noun or NP.

(4) So they just keep their mouth shut and avoid to speak and practice a foreign language. This attitude is not good. Making mistakes is very natural when one learns to speak a language. (NICKLE)

Among these shell nouns, those that entailed GM were coded as Nominalization. Specifically, the nouns that referred back to a process/action or a property/quality were coded as Process as Thing and Quality as Thing respectively as in (5) and (6).3)

3) While the nominalizations identified were oftentimes nouns derived from a verb or adjective used in the preceding text as in (5) and (6) (see underlines), derivation was not a requisite condition for GM. A head noun in the this + noun construction was counted as a nominalization if it involved a conversion from a process/property to an entity regardless of whether the referent contained a verb or adjective belonging 
(5) I believe that the juvenile death penalty must be done away with. My rationale for this belief is for the most part grounded on the fragility of juveniles … (Process as Thing) (NICKLE)

(6) Each year the field of sports becomes more and more competitive. With this competitiveness, comes the desire to stand out from the crowd and be the best athlete in the world. (Quality as Thing) (LOCNESS)

Nouns were categorized as Adverbial when they were used as part of adverbial phrases such as for this reason, in this way, and in this respect, which are usually used as single lexical items. Finally, the rest of the nouns occurring in the this + noun construction were coded as Simple Deictic. Nouns in this category referred to a single nominal group denoting a physical entity or were repetitions of the nouns stated earlier in the preceding text. Therefore, the same nouns were sometimes categorized differently depending on their referent. For example, the two instances of process in the example (7) were categorized differently with the first as Shell Noun and the second as Simple Deictic.

(7) Throughout the world a wind of change is apparent, but especially so in Europe. This process will continue and Europe the rest of the world will evolve with or without the participation of Britain in this process. (NICKLE)

Aside from the three categories described above, nouns signaling the writer's stance were classified into two types (Biber et al. 1999). Nouns stating the status of information in terms of certainty, precision, and actuality were coded as epistemic (e.g., possibility, evidence, hypothesis, claim) while nouns revealing personal feelings and attitudes as attitudinal (e.g., problem, solution, atrocity). Figure 1 below illustrates classifications of the nouns following this and types of stance expressed in the nouns. 


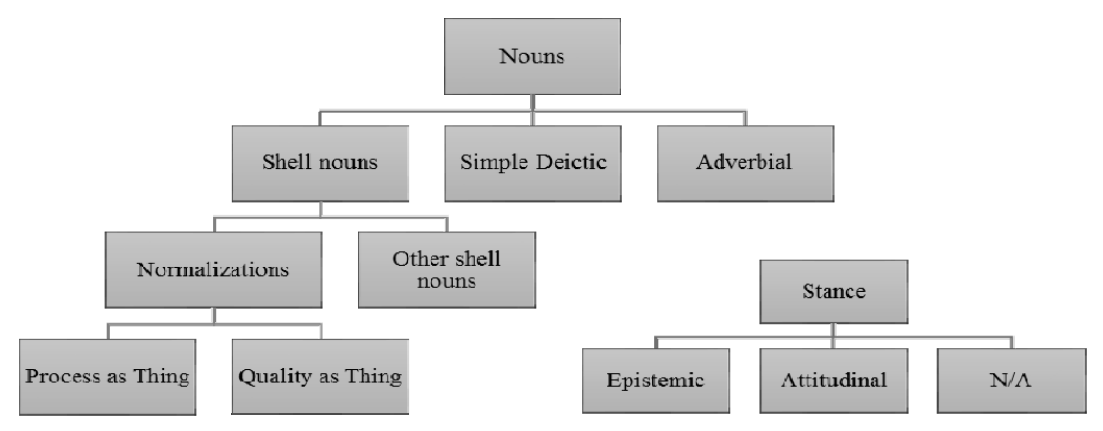

Figure 1. Classifications of nouns following this.

Once all instances of attended this were classified into the categories described above, the frequency counts were normed per 200,0004) words for direct comparison between the two corpora. To determine the statistical significance of differences in frequency between the two corpora, log-likelihood (LL) was computed for each category.5)

Finally, in addition to quantitative tallying of instances, qualitative analysis of actual uses of attended this was conducted with some of the most frequent shell nouns in NICKLE to explore patterns of misuse in the demonstrative construction and shell nouns therein.

\section{Results and discussion}

\subsection{Types and frequencies of nouns attending this}

In NICKLE, 570 true hits of attended this were found while 997 hits were found in LOCNESS (see Table 2 below). This confirms the findings

4) The choice of this specific figure was made for a practical reason. The figure 200,000 is relatively close to the sizes of the two corpora and roughly a midpoint between them, so normed frequency counts would not be drastically different from their raw counts from either corpus.

5) Log-likelihood is here used to determine whether the greater frequency of a linguistic item in one corpus than another is statistically significant (Jones \& Waller, 2015). In other words, it determines whether the item is statistically overused or underused in one corpus relative to the other. 
of previous studies (e.g., S-Y Oh, 2012; Petch-Tyson 2000) where NNS students used patterns of demonstrative + noun for anaphoric reference much less frequently than their NS counterparts.

When we look at the types of nouns attending this, clear differences between the two groups of writers emerge. First, while the Korean university students significantly underused the this + noun construction, their underuse of shell nouns is more pronounced as indicated by the highest LL value (61.30) in Table 2. Second, by contrast, they overused the construction as part of adverbial phrases relative to their NS counterparts.

Table 2. Types of Nouns Following This6)

\begin{tabular}{c|c|c|c|c|c|c|c}
\hline & \multicolumn{2}{|c|}{ NICKLE } & \multicolumn{2}{c|}{ LOCNESS } & LL & sig. & $+/-$ \\
\hline \hline & raw freq. & normed & raw freq. & normed & & & \\
\hline Adverbial & 103 & 108.3 & 84 & 73.2 & 7.14 & $* *$ & + \\
Simple Deictic & 270 & 283.8 & 460 & 400.9 & 20.80 & $* * *$ & - \\
Shell Noun & 197 & 207.1 & 453 & 394.8 & 61.30 & $* * *$ & - \\
Total & 570 & 599.2 & 997 & 868.8 & 51.51 & $* * *$ & - \\
\hline
\end{tabular}

Note. $\mathrm{LL}=\log$ likelihood; sig. $=$ significance $(*: p<0.05, * *: p<0.01, * * *: p<$ $0.001)$; "+" indicates overuse in NICKLE and "-" indicates underuse; normed = normed per 200,000 words

These differences are displayed more explicitly with the figures presented in percentage. As seen in Figure 2, shell nouns made up a smaller portion in NICKLE (34.6\% versus $45.4 \%$ ) while adverbial use accounted for a larger chunk (18.1\% versus $8.4 \%$ ) as compared to those in LOCNESS. In previous studies that examined published research articles (Gray 2010; Gray \& Cortes 2011), shell nouns accounted for a range of 40 to $45 \%$ of all nouns occurring in the same construction. This may indicate the Korean university students did not employ the this + noun construction for text reference and argument development as frequently as the NS student writers and the published researchers.

6) Frequencies reported in Table 2 are sums of head nouns extracted from the following syntactic patterns: this + noun, this + modifier + noun, and this + species noun (kind/sort/type/form $)+$ of + noun 


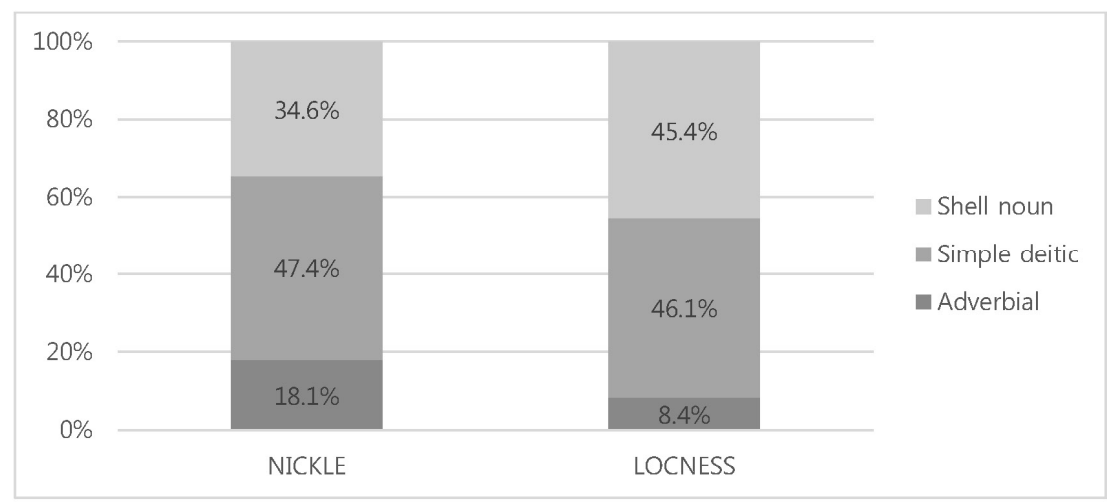

Figure 2. Percentages of each noun type in the two corpora.

By contrast, the proportion of adverbial use in NICKLE was significantly high relative to previous studies (Gray 2010; Gray \& Cortes 2011; S-Y Oh 2012) in which corresponding proportions were in the range of 2 to $4 \%$. The big gap is attributable in part to the difference in academic genre of constituent texts making up each corpus (i.e., argumentative writing versus research articles) but the NICKLE number, 18.1\%, still turned out to be much higher than the $8.4 \%$ of LOCNESS, which is also a corpus of student argumentative writing. The high proportion of adverbial use suggests that much of Korean EFL writers' use of the construction is formulaic, used habitually as a transition rather than as a motivated choice for argument development. For example, one essay in NICKLE, about 900 word long, had seven instances of attended this, all of which were either simple deictic or of adverbial use without a single instance of shell noun. Some of the adverbial uses are illustrated in (8) below:

(8) -... who are confronted with an entrance examination or an employment examination lose hair. In this case, most of them are young and it is highly possible for them to be a baldhead. ... It is true that the number of baldheads in Western is larger than those in Eastern. For this reason, Western baldheads are less ashamed of themselves than Eastern baldheads. (NICKLE) 


\subsection{Use of shell nouns}

The two corpora shared many of the shell nouns identified as shown in Table 3 (see bold-faced nouns in the top 20 frequent shell nouns). It hardly comes as a surprise since shell nouns are often disciplinary-neutral general nouns that occur commonly in academic prose (Gray 2010). In NICKLE, however, some of the general nouns highly expected to occur in argumentative writing are missing on its top 20 list. For example, the word argument, which was the most frequent shell noun attending this in LOCNESS, never occurred in the demonstrative construction in NICKLE7). This was also the case with statement, idea, view, claim and question, which were often identified as most frequent shell nouns in the literature (e.g., Charles 2003; Francis 1994; Gray 2010). Taken together with the frequency results presented above, this indicates that while the Korean writers made text reference using this + noun less frequently than their NS counterparts, when they did, they often used different labels in naming the referent or avoided using certain nouns for a label. The absence of some of these nouns is further discussed in the next section about stance construction.

Table 3. Frequent Shell Nouns in this + Noun

\begin{tabular}{c|c|c|c}
\hline & Types & Tokens & \multicolumn{1}{|c}{20 most frequent shell nouns (frequency) } \\
\hline \hline NICKLE & 104 & 197 & $\begin{array}{l}\text { problem (15), situation (13), fact (12), } \\
\text { phenomenon (6), issue (5), method (5), } \\
\text { process (5), matter (4), trend (4), attitude (3), } \\
\text { experience (4), condition (3), effort (3), } \\
\text { example (3), point (3), system (3), thought (3), } \\
\text { way (3), activity (2), advantage (2) }\end{array}$ \\
\hline LOCNESS & 209 & 453 & $\begin{array}{l}\text { argument (24), issue (21), statement (18), } \\
\text { problem (15), idea (14), point (13), view (12), } \\
\text { claim (8), fact (8), process (8), situation (8), } \\
\text { question (7), topic (7), action (6), example (6), } \\
\text { system (6), attitude (5), behavior (5), } \\
\text { method (5), subject (5) }\end{array}$ \\
\hline
\end{tabular}

7) The noun argument was extremely underused in NICKLE as a whole. The word occurred only 7 times in NICKLE while 239 times in LOCNESS. 
Turning now to the types of shell nouns, nominalizations turned out to be far rarer in NICKLE than in LOCNESS (see Table 4 below) as with shell nouns as a whole. However, the proportion of nominalizations within shell nouns was even smaller in NICKLE (27.9\% versus 34.7\%). As for the types of GM, Process as Thing occurred about four times more frequently than Quality as Thing in both corpora.

Table 4. Nominalizations Attending this in the Two Corpora

\begin{tabular}{c|c|c|c|c|c|c|c}
\hline Nominalizations & \multicolumn{2}{|c|}{ NICKLE } & \multicolumn{2}{c|}{ LOCNESS } & LL & sig. & $+/-$ \\
\hline \hline & raw freq. & normed & raw freq. & normed & & & \\
\hline P à T & 44 & 46.3 & 123 & 107.2 & 25.56 & $* * *$ & - \\
Q à T & 11 & 11.6 & 34 & 29.6 & 8.41 & $* *$ & - \\
Total & $55(27.9 \%)$ & 56.8 & $157(34.7 \%)$ & 136.8 & 33.90 & $* * *$ & - \\
\hline
\end{tabular}

Note. $\mathrm{P}$ à $\mathrm{T}=$ process as thing; $\mathrm{Q}$ à $\mathrm{T}=$ quality as thing; $\mathrm{LL}=\log$ likelihood; sig. $=$ significance $\left(*: p<0.05,{ }^{* *}: p<0.01, * * *: p<0.001\right)$; “+” indicates overuse in NICKLE and "-" indicates underuse; normed. = normed per 200,000 words; * percentage figures here represent the proportion of nominalizations in shell nouns.

The relatively high frequency of nominalizations in LOCNESS can be attributed to several nouns such as argument, action, and behavior, repeatedly employed as a tool for argument development. For example, the word argument occurred 24 times as an instance of GM as in (9) below:

(9) The pro-gun activists, however, argue that firearms actually prevent murders, rapes and burglaries. The problem with this argument is that it lacks statistical verification. (LOCNESS)

In this text, the writer compresses a dynamic process expressed in a clause (i.e., pro-gun activists argue that -..) into an entity (i.e., the noun argument), now reconstrued as a static object for analysis and evaluation in the subsequent discourse. This pattern occurred very frequently in LOCNESS particularly with the word argument, which is hardly surprising given the nature of argumentative essays it was compiled from. However, along with shell nouns in general, the use of nominalizations in this pattern was not observed as often in NICKLE. This suggests that NICKLE writers 
might have been overall unaware of the functions of nominalization in creating cohesion and argument development or not yet reached the level required to be able to manipulate lexico-grammatical configurations to fit their rhetorical needs.

\subsection{Stance manifested in shell nouns}

A total of 59 tokens of stance nouns were identified from all shell nouns occurring in the demonstrative construction in NICKLE while 170 tokens in LOCNESS (62 versus 148 when normed per 200,000 words). Compared against the total number of shell nouns, stance nouns made up a slightly smaller portion in NICKLE (about 30\%) than in LOCNESS (about 38\%). In other words, when they used shell nouns, the NICKLE writers tended less than their NS counterparts to incorporate their stance towards the propositions being encapsulated.

When we look at the types of stance expressed, more differences emerge. As seen in Figure 3 below, NICKLE showed a slight preponderance of attitudinal over epistemic stance while LOCNESS showed the opposite pattern.

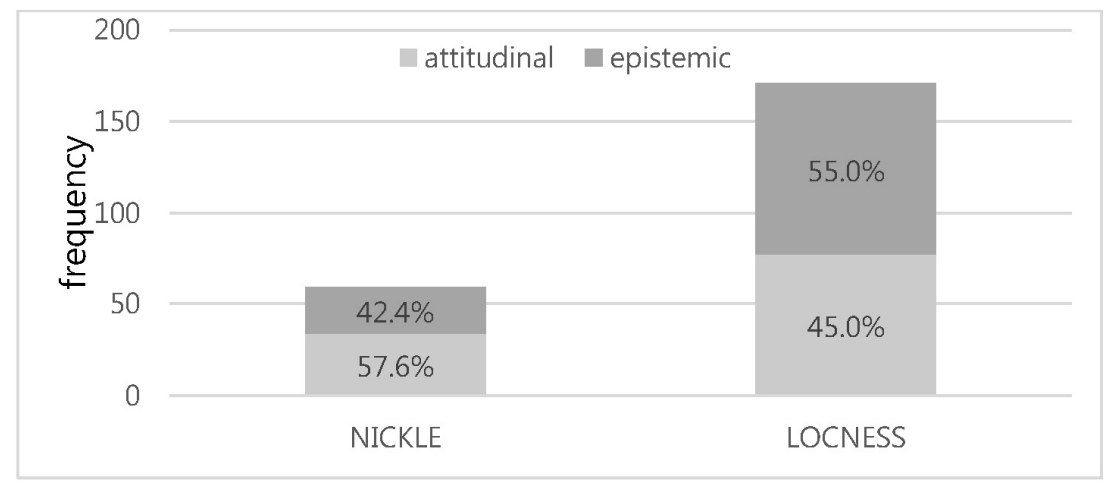

Figure 3. Distribution of stance types in shell nouns.

Based on corpora of doctoral theses from natural and social science disciplines, Charles (2003) found some disciplinary differences in the types of stance expressed in sentence-initial this + noun instances. While epis- 
temic stance nouns were more frequent in both corpora, the social science corpus featured a greater proportion of attitudinal stance nouns. This finding is not entirely unexpected in that research theses in natural science are likely to have less need for and means of expressing personal attitudes and feelings. Likewise, the preponderance of attitudinal stance in NICKLE is not surprising given the nature of argumentative writing, which more often than not entails value judgement and expression of personal opinion. However, despite being in the same genre of argumentative essays, LOCNESS still showed a predominance of epistemic stance just as in the corpora of research articles in Charles (2003) above. The contrast between the two groups may be attributed in part to the different levels of register awareness. Comparative studies on textual features of argumentative essays by NS and NNS students (e.g., Gilquin \& Paquot 2008; Hinkel 2005; C-I. Yoon 2015) revealed that NNS writers' essays included more involvement and overstatement features, which are more associated with spoken registers while NS texts had more instances of linguistic devices for expressing a degree of doubt and tentativeness and for impersonal objectivity, which is generally expected in academic prose (Hyland \& Milton 1997). The differences in the use of epistemic stance nouns by the two groups of the present study may be taken to be in line with these findings of the prior studies.

Table 5. Shell Nouns of Epistemic Stance

\begin{tabular}{c|c|c|l}
\hline & Types & Tokens & \multicolumn{1}{|c}{ Epistemic shell nouns (frequency) } \\
\hline \hline NICKLE & 7 & 25 & $\begin{array}{l}\text { fact (12), trend (5), thought (3), possibility (2), } \\
\text { paradigm (1), principle (1), tendency (1) }\end{array}$ \\
\hline LOCNESS & 20 & 94 & $\begin{array}{l}\text { argument (24), idea (14), view (12), claim (8), } \\
\text { fact (7), evidence (4), scenario (4), theory (4), } \\
\text { debate (3), knowledge (3), proof (2), thought (2), } \\
\text { belief (1), controversy (1), hypothesis (1), } \\
\text { ideology (1), interpretation (1), norm (1), rule (1), } \\
\text { trend (1) }\end{array}$ \\
\hline
\end{tabular}

It would be worthwhile here to look at the distributions of epistemic nouns more closely. Epistemic stance shell nouns were, as defined in this study, used to mark precision, certainty or actuality of the propositions 
they referred to and the LOCNESS writers used a much greater variety of epistemic nouns as shown in Table 5 above. This suggests that the NS students were better able to differentiate the status of the information they deliver through shell nouns in terms of precision and certainty. In other words, the LOCNESS writers had a greater tendency to evaluate the proposition being discussed and name it with a proper label based on that evaluation. For example, what someone says can be reconstrued as a view, claim, theory, or hypothesis depending on the writer's judgement about the epistemic status of the information encapsulated and intention on how to orient readers in its understanding. In NICKLE, epistemic stance nouns used in this + noun are quite limited with fact accounting for nearly $50 \%$ of all instances (see Table 5). The lack in the variety and frequency of these labels in NICKLE suggests that the Korean university students may have been largely unaware of the need for epistemic evaluation or simply lacked a lexical repertoire required for nuanced choice of labels.

4.4. Inappropriate uses of the this + noun construction for text reference

Although a considerable portion of this + noun instances in NICKLE were used appropriately and effectively, many instances still showed patterns of inappropriate use. In this section, some of most common patterns are reported for the purpose of identifying the areas where help is needed most.

The first major pattern identified is a missing or unclear referent. In (10), the use of the phrase to come to this conclusion makes the reader go back to the preceding text to locate what it refers to. However, nowhere in the preceding sentences is what can be seen as its referent:

(10) The word 'globalization' has been made and used quite recently to describe the rapid changes of each country, and its increasing reliance on international society. But we have to examine carefully that what does 'global' means, and how could we improve our lives with globalization. I want to examine be- 
low especially in the aspect of Korean economy, to come to this conclusion. (NICKLE)

There were cases where the referent was not outright missing as in (10) but was vague or confusing leaving the reader wondering what the demonstrative construction exactly points to. Some frequent shell nouns in NICKLE such as problem and situation were often used to refer to something discussed earlier in the essay so loosely that what is being encapsulated in that shell is not clearly identifiable, which is illustrated in (11):

(11) So, protecting environment is very important! Nowadays, this matter gets more and more important. Then, what can we do to protect the environment? Let me talk about this problem in several subjects.

Given the negative attitudinal stance the word problem connotes, this problem in (11) may roughly refer to the problem of pollution in our environment, which is not stated explicitly in the prior discourse. Meanwhile, considering the flow of sentences, the phrase may be taken to refer to the immediately preceding proposition (i.e., what we can do to protect the environment). In that case, it would be more appropriate to label it as a matter, subject or issue rather than as a problem, which may deliver an unnecessary or unintended connotation.

The second pattern is the use of a shell noun that does not sit well logically with the subsequent discourse. This pattern is frequently observed with the use of the noun fact, the most frequent shell nouns in NICKLE. The noun fact in (12) is used as a shell containing the whole preceding text and is linked in a causal relation to the subsequent proposition. However, considering the logical relations between the propositions in (12), it seems that what gives the stated advantage is not the fact itself but the increasing ease of Internet access.

(12) Many methods for easy and convenient internet connection are developed. As a result, internet users do not include only ex- 
pert users but also many uneducated people and children. This fact gives us the advantage of communicating with various kinds of people.

Stronger cohesion and better reader understanding of the causal relation would be created if the writer chose a shell noun that points to the more specific part of the preceding discourse that can be directly linked to the subsequent proposition. This may require the use of a shell noun construction with modification that adds specificity (e.g., this growing ease in Internet access). Or if the writer still intends to encapsulate the entire preceding text in a demonstrative structure, an unattended this would sound better.

This example and others involving frequent shell nouns (e.g., problem, situation, fact), which are not discussed here for lack of space, suggest that faced with an inability to come up with proper shell nouns to use in the demonstrative construction, the Korean EFL writers may have resorted, rather habitually, to frequent general nouns that they picked up through repeated exposure and use, probably without considering specifically identifiable referents and the stance these nouns may signal.

The last pattern to discuss concerns nominalization. In several instances of nominalization in NICKLE, there were varying degrees of semantic mismatch between the nominalizations and the process or quality that they represented. In (13) below, the use of this request makes the reader assume that there was some form of official request for conversation, which is not directly stated in the preceding text. Rather, the process of attempting a conversation is directly transformed into an entity noun request creating a gap in textual cohesion.

(13) Recently, Tibet government in exile modified their purpose from a perfect independence to a substantial autonomy and is attempting a conversation with China. Surely even this request is not accepted by China, Tibetans who have been holding their own spiritual world, they are seen to be going to continue their activities by means of nonviolence resistance. 
Taken together, the three patterns examined above reveal that in the use of this + noun, many Korean EFL students may have difficulties deciding what information to encapsulate in what label to develop cohesive and logical arguments, or may simply be unaware of the need to do so. This interpretation of the findings carries important pedagogical implications, which are discussed below.

\subsection{Pedagogical implications}

All these findings indicate the need for greater exposure to and explicit instruction in the functions and usages of the this + noun construction and the range of lexico-grammatical options learners can choose from depending on their intention regarding authorial voice and rhetorical effect.

Among others, EAP and EFL writing instruction can include activities to raise students' awareness of the functions of this + noun alongside other demonstrative structures. Specifically, as Hinkel (2001) suggests, students should be provided with opportunities to practice linking demonstratives and shell nouns to specific parts of the discourse while reading academic texts, and using the constructions as tools for cohesive and rhetorical effect in their own academic writing.

As evident in the results of the study, many Korean EFL writers may be unaware of the need for incorporating appropriate stance into the label encapsulating the preceding information and lack a lexical repertoires from which to choose appropriate labels. Thus, students should be gradually introduced to a wide range of nouns frequently used as shells in academic prose and how those nouns may differ in signaling the writer's epistemic and attitudinal stance, thereby influencing the reader's interpretation of the proposition being discussed.

This study also revealed that the Korean university writers' use of nominalization within the this + noun construction is very infrequent. As Liardét $(2013,2015)$ showed, the ability to effectively use nominalization for GM may not necessarily come with increasing proficiency, but rather require explicit instructional support as a specific skill needed for academic writing. In this regard, as Rhysina-Pankova $(2010,2015)$ argues, vocabulary in- 
struction in EAP courses should go beyond teaching rules of deriving nouns from other word classes and explain the implications of using nominalization in meaning making and argument development. One way of doing so is that nominalization is introduced as a safe option to go for when having difficulty choosing a proper shell noun in a given context. For example, on the basis of the results of the present study, it would be a reasonable guess that not a small number of NICKLE writers may choose a frequent general noun such as fact to fill in the blank in the following excerpt from NICKLE. Here, the noun fact would not be the most effective choice in terms of clarity in the reference and consequently cohesion.

(14) If a new university [was] built in our town, various people like professors and students from other towns would move here. This will make our town more interesting.

Instead of resorting to one of the general nouns habitually used, students may be guided to nominalize a process or property being described in the preceding text. Thus, here in (14), a better choice would be, as the actual writer did, to use the shell noun phrase variety of people, which is created by nominalizing various people appearing in the preceding sentence.

Finally, compressing lengthy information into a single nominal can achieve economy in text formulation but may also cause the reader difficulty in identifying in a complex text what exactly is referred to (Biber \& Gray 2010; Swales 2005). Students should be made aware of this trade-off between economy and clarity and learn to enhance clarity through pre-modification (e.g., adjective or noun modifier) and/or post-modification (e.g., prepositional phrase) of the shell noun. Swales (2005) offers an illustrative example of cumulative addition of post-modification:

The students said they wanted more tests.

- This request surprised the instructor.

- This request for more tests surprised the instructor.

- This request by the students for more tests surprised the instructor. 
This type of exercise will benefit students by allowing them to practice adding or removing different levels of modification and to strike a balance between economy and clarity where they see fit.

\section{Conclusion}

The present study examined the use of this + noun in NICKLE, a corpus of Korean university students' English argumentative essays with a particular focus on the distributions of shell nouns and nominalizations used for text reference within the construction. The qualitative and quantitative findings from the corpus were compared against those from LOCNESS, a corresponding corpus of NS student argumentative writing. Results showed that while the Korean university students made much less use of this + noun for anaphoric text reference than their NS counterparts, their use of the construction was often less successful in creating cohesion and constructing proper stance in ways valued in academic writing. This is attributed in large part to their under- and mis-use of shell nouns and nominalizations within the construction. Specifically, the limited range of general nouns (e.g., problem, situation, fact) used in the construction indicates the Korean writers' use of shell nouns was often habitual or formulaic rather than strategic or motivated.

As such, the results of the study shed light on where EFL writers in tertiary education need help in using the demonstrative structure and this paper has also made some practical suggestions about what can be done in EAP and EFL composition classrooms. This type of assistance in the proper use of shell nouns and nominalization will benefit students by helping them improve their abilities to make cohesive text references and present authorial voice in appropriate manners. Greater use of those nominal features will ultimately enhance students' abilities to make their texts more nominal-oriented and efficient, which is highly valued in modern academic writing.

Although this study offers some valuable findings and pedagogical implications, it also has some limitations. Among others, shell nouns and 
nominalization have been examined only in the narrow context of this + noun. So the characteristics observed regarding the Korean writers' use of shell nouns and nominalizations cannot be extended to other constructions and contexts in which they occur. Another major limitation was that the coding of data was conducted by the researcher alone for time and practical constraints. Although the researcher took special care to apply the coding criteria as consistently as possible, the lack of additional coders might have biased the classifications of data. Future studies may therefore expand the scope and investigate the use of these academic nominal features in more diverse lexico-grammatical contexts, with greater methodological rigor including the use of multiple coders.

\section{References}

Anthony, Laurence. (2014). AntConc (Version 3.4.3) [Computer Software]. Waseda University. Available from http://www.laurenceanthony.net/.

Baratta, Alexander M. (2010). Nominalization development across an undergraduate academic degree program. Journal of Pragmatics 42.4, 1017-1036.

Biber, Douglas, Stig Johansson, Geoffrey Leech, Susan Conrad, and Edward Finegan. (1999). Longman Grammar of Spoken and Written English. Longman.

Biber, Douglas and Bethany Gray. (2010). Challenging stereotypes about academic writing: Complexity, elaboration, explicitness. Journal of English for Academic Purposes 9.1, 2-20.

Charles, Maggie. (2003). 'This mystery ...': A corpus-based study of the use of nouns to construct stance in theses from two contrasting disciplines. Journal of English for Academic Purposes 2, 313-326.

Francis, Gill. (1994). Labelling discourse: an aspect of nominal-group lexical cohesion. In Malcolm Coulthard, ed., Advances in written text analysis, 83-101. Routledge.

Geisler, Cheryl, David S. Kaufer, and Erwin R. Steinberg. (1985). The unattended anaphoric "this": When should writers use it? Written Communication 2, 129-155.

Gilquin, Gaëtanelle and Magali Paquot. (2008). Too chatty: Learner academic writing and register variation. English Text Construction 1.1, 41-61.

Gray, Bethany. (2010). On the use of demonstrative pronouns and determiners as 
cohesive devices: A focus on sentence-initial this/these in academic prose. Journal of English for Academic Purposes 9, 167-183.

Gray, Bethany and Viviana Cortes. (2011). Perception vs. evidence: An analysis of this and these in academic prose. English for Specific Purposes 30.1, 31-43.

Halliday, Michael. A. K. and Ruqaiya Hasan. (1976). Cohesion in English. Longman.

Halliday, Michael. A. K. and James R. Martin. (1993). Writing science: Literacy and discursive power. The Falmer Press.

Hinkel, Eli. (2001). Matters of cohesion in L2 academic texts. Applied Language Learning, 12.2, 111-132.

(2005). Hedging, inflating, and persuading in L2 academic writing. Applied Language Learning 15, 29-53.

Hyland, Ken and John Milton. (1997). Qualification and certainty in L1 and L2 students' writing. Journal of Second Language Writing 6, 183-205.

Ivanic, Roz. (1991). Nouns in search of a context. International Review of Applied Linguistics 29.2, 93-114.

Jones, Christian and Daniel Waller. (2015). Corpus linguistics for grammar: A guide for research. Routledge.

Liardét, Cassi L. (2013). An exploration of Chinese EFL learner's deployment of grammatical metaphor: Learning to make academically valued meanings. Journal of Second Language Writing 22.2, 161-178.

(2015). Academic Literacy and Grammatical Metaphor: Mapping Development. TESOL International Journal 10.1, 29-46.

Nini, Andrea. (2014). Multidimensional analysis tagger (Version 1.2) [Computer Software]. Available from http://sites.google.com/site/multidimensionaltagger.

Oh, Sun-Young. (2012). This and these in Korean graduate students' academic writing. Language Research 48.3, 715-750.

Ryshina-Pankova, Marianna. (2010). Toward mastering the discourses of reasoning: Use of grammatical metaphor at advanced levels of foreign language acquisition. The Modern Language Journal 94.2, 181-197.

(2015). A meaning-based approach to the study of complexity in L2 writing: The case of grammatical metaphor. Journal of Second Language Writing 29, 51-63.

Petch-Tyson, Stephanie. (2000). Demonstrative expressions in argumentative discourse. In Simon Botley and Tony McEnery, eds., Corpus-based and computation approaches to discourse anaphora, 43-64. John Benjamins.

Schleppegrell, Mary J. (2004). Technical writing in a second language: The role of grammatical metaphor. In Louise J. Ravelli and Robert A. Ellis, eds., Analysing 
academic writing: Contextualized frameworks, 172-189. Continuum.

Schmid, Hans-Jörg. (2000). English abstract nouns as conceptual shells: From corpus to cognition. Mouton de Gruyter.

Swales, John M. (2005). Attended and unattended "this" in academic writing: A long and unfinished story. ESP Malaysia 11, 1-15.

Wulff, Stefanie, Ute Römer, and John Swales. (2012). Attended/unattended this in academic student writing: Quantitative and qualitative perspectives. Corpus Linguistics and Linguistic Theory 8.1, 129-157.

Yoon, Choongil. (2015). Writing Like Speaking: Spoken Register Features in Korean EFL Learners' Argumentative Writing. Korean Journal of Applied Linguistics 31.4, 153-179.

Choongil Yoon

Paramita College, Dongguk University (Gyeongju Campus)

123 Dongdae-ro, Gyeongju-si, Gyeongsangbuk-do, 38067, Korea

Email: chongal2@hotmail.com

Received: February 23, 2017

Revised version received: April 2, 2017

Accepted: April 16, 2017 
